\title{
A Novel Pan-Flavivirus Detection and Identification Assay Based on RT-qPCR and Microarray
}

\author{
Ariel Vina-Rodriguez, ${ }^{1}$ Konrad Sachse, ${ }^{2}$ Ute Ziegler, ${ }^{1}$ Serafeim C. Chaintoutis, ${ }^{1,3}$ \\ Markus Keller, ${ }^{1}$ Martin H. Groschup, ${ }^{1}$ and Martin Eiden ${ }^{1}$ \\ ${ }^{1}$ Institute for Novel and Emerging Infectious Diseases, Friedrich-Loeffler-Institut (Federal Research Institute for Animal Health), \\ Insel Riems, Greifswald, Germany \\ ${ }^{2}$ Institute of Molecular Pathogenesis, Friedrich-Loeffler-Institut (Federal Research Institute for Animal Health), Jena, Germany \\ ${ }^{3}$ Diagnostic Laboratory, Department of Clinical Sciences, School of Veterinary Medicine, Faculty of Health Sciences, \\ Aristotle University of Thessaloniki, Thessaloniki, Greece
}

Correspondence should be addressed to Martin Eiden; martin.eiden@fli.de

Received 20 December 2016; Accepted 7 February 2017; Published 24 May 2017

Academic Editor: Satish B. Nimse

Copyright (c) 2017 Ariel Vina-Rodriguez et al. This is an open access article distributed under the Creative Commons Attribution License, which permits unrestricted use, distribution, and reproduction in any medium, provided the original work is properly cited.

\begin{abstract}
The genus Flavivirus includes arthropod-borne viruses responsible for a large number of infections in humans and economically important animals. While RT-PCR protocols for specific detection of most Flavivirus species are available, there has been also a demand for a broad-range Flavivirus assay covering all members of the genus. It is particularly challenging to balance specificity at genus level with equal sensitivity towards each target species. In the present study, a novel assay combining a SYBR Greenbased RT-qPCR with a low-density DNA microarray has been developed. Validation experiments confirmed that the RT-qPCR exhibited roughly equal sensitivity of detection and quantification for all flaviviruses tested. These PCR products are subjected to hybridization on a microarray carrying 84 different oligonucleotide probes that represent all known Flavivirus species. This assay has been used as a screening and confirmation tool for Flavivirus presence in laboratory and field samples, and it performed successfully in international External Quality Assessment of NAT studies. Twenty-six Flavivirus strains were tested with the assay, showing equivalent or superior characteristics compared with the original or even with species-specific RT-PCRs. As an example, test results on West Nile virus detection in a panel of 340 mosquito pool samples from Greece are presented.
\end{abstract}

\section{Introduction}

The genus Flavivirus contains nearly 70 recognized viruses, many of which infect humans and economically important animals [1]. Flaviviruses, such as Dengue virus (DENV) [2] and Yellow fever virus (YFV) [3], have been a common cause of devastating diseases in tropical and less developed countries, but in recent years the emergence of flaviviral zoonoses was observed worldwide. Examples include the occurrence of West Nile virus (WNV) in the United States [4], Japanese encephalitis virus (JEV) in Australia [5], and Usutu virus (USUV) [6], WNV [7], and DENV [2] in Europe. Recently, Zika virus (ZIKV) also expanded into Southern America, with reports of detection in Europe and USA [8].
Large surveillance and early warning systems commonly applied in European countries and around the world could benefit from a more sensitive and broader range screening method. Both mosquito pools and (sentinel) birds are common targets of massive screening for arbovirus, particularly for flaviviruses like WNV or USUV [6, 9, 10]. Rapid virus identification and quantification are crucial for accurate diagnosis of ongoing infections, treatment selection, and followup, as well as for selection and timely introduction of control measures in outbreaks scenarios. In this context, highly parallel detection technologies, such as DNA microarrays, are gaining importance [11-20].

Like RNA viruses in general, flaviviruses are distinguished by extensive genetic heterogeneity, which implies 
classification into subunits, for example, genotypes and lineages, each with distinct epidemiological or clinical significance. This heterogeneity represents a major challenge in primer and probe design for PCR and DNA microarray assay development.

In the present study, we have optimized a pan-Flavivirusspecific SYBR Green-based real-time reverse-transcription polymerase chain reaction (RT-qPCR) [21]. The amplification is subsequently complemented with hybridization on a low-density DNA microarray, which exploits the genetic heterogeneity contained in the internal segment of the PCR amplicon, thus allowing rapid identification of flaviviruses from clinical or field samples.

\section{Materials and Methods}

2.1. Viral Samples and RNA Extraction. The 26 Flavivirus strains to be used as reference were collected and stored at $-80^{\circ} \mathrm{C}$ until being processed as follows.

African green monkey kidney (Vero) cells (Collection of Cell Lines in Veterinary Medicine, Friedrich-LoefflerInstitut, Insel Riems, Greifswald, Germany) were infected with viruses in biosafety $\mathrm{L} 3^{* *}$ laboratory facilities, and cell culture supernatants were collected and inactivated in Buffer AVL (QIAGEN, Hilden, Germany) as previously described $[22,23]$. The WNV strains lineage 1a-NY99 (ac. AF196835) and Dakar, lineage 1b-Kunjin (ac. D00246) and lineage 2Uganda 1937 (ac. M12294), B956 (ac. AY532665), Sarafend (ac. AY688948), and goshawk Austria 361/10 (2009) (ac. HM015884) were reused from our previous works [22-24]. The strains USUV Germany 2011 (BH/65) (ac. HE599647), YFV 17D, JEV, TBEV Langat, Malaysia, 1956 (ac. AF253419), and Murray Valley encephalitis virus (MVEV) were reused from another work [25]. USUV Austria 2001 (939/01) and Germany 2011 (939/01) were taken from [26] and JEV Nakayama (ac. EF571853) and TBEV Neudoerfl (ac. U27495) from [27].

Additionally, the following strains were obtained from the Health Protection Agency, Salisbury, United Kingdom: WNV lineage 2, MB 1957; SLEV; YFV "French Neurotrop" and LolIl (\#780). JEV Nakamura was kindly provided by A. Müllbacher (John Curtin School of Medical Research, Canberra, Australia). RNA from ZIKV and DENV 1, 2, 3, and 4 viruses was provided by P. Despres (Flavivirus Unit, Institute Pasteur, Paris, France), while F. Hufert and M. Weidmann (Institute for Virology, Göttingen, Germany) kindly provided the viruses TBEV Absettarov, 1951 (ac. AF091005), TBEV Aina, 1963 (ac. AF091006), and TBEV Hypr, 1953 (ac. U39292).

RNA was extracted with the RNeasy Mini Kit, or the QIAamp Viral RNA Mini Kit (QIAGEN, Hilden, Germany), according to the manufacturer's protocol. A synthetic RNA was used as internal extraction control (IC) [28]. The NY99 RNA was used to create an external calibrator curve, which in turn was calibrated using the $5^{\prime}$ UTR WNV-specific RT-qPCR [22].
2.2. Selection of Primers and Probes. Nearly 200 complete Flavivirus genome sequences were obtained from the NCBI Nucleotide database by the end of 2010. Very similar sequences (more than $98 \%$ identity) were excluded. The sequences were aligned using CLUSTAL X [29] (accessed from BioEdit software v.7.0.5.3) [30] and VectorNTI Advanced v.10 (Invitrogen, Carlsbad, CA, USA). This alignment was manually curated using both the nucleotide and the deduced amino acid sequences and extended by adding partial sequences to reach a total of more than 400 , so as to represent the NS5 gene of all known species, including most subtypes or lineages (a regularly updated version is available at Flavivirus GitHub site (https://github.com/qPCR4vir/Flavivirus)).

VisualOligoDeg (https://github.com/qPCR4vir/VisualOliDeg) was used to facilitate visualization and selection of appropriate oligonucleotides hybridizing to sequences of a given. The NS5 regions (spanning nucleotides 9040 to 9305 of AF196835) of the aligned sequences were imported into this workbook and were manually classified into major groups (MB: mosquito borne; TB: tick borne; and insect-only), virus groups (JEVG, YFVG, TBEVG, etc.), species (WNV, JEV, YFV, TBEV, etc.), and in some cases lineages (like WNV-1 or WNV-2, etc.) or genotypes.

Alongside species-specific RT-PCRs [31], broader, genusspecific RT-PCR protocols have been also reported [19, 21, 32, 33]. A genus-specific Taq-Man RT-PCR for Flavivirus detection was modified [21], with primer sequences optimized using VisualOligoDeg. It targets conserved flanking regions with an internal region with sufficient variability to enable virus identification by sequencing the amplicon. The original sequences were adapted to consistently amplify most of the Flavivirus members resulting in degenerate primers PFlav-fAAR (TACAACATGATGGGAAAGAGAGAGAAㅅA from 9040 to 9068 of AF196835) and PFlavrKR (GTGTCCCAKCCRGCTGTGTCATC from positions 9305 to 9283 of AF196835).

A total of 50 probes with a Tm around $55^{\circ} \mathrm{C}$ were selected. A second set of sequences was also selected as a replacement, in case of failure of first-set sequences. The candidate sequences were submitted to the manufacturer for a final in silico evaluation of properties (homogenous hybridization, discriminatory potential, etc.). As a result, all 84 sequences were found suitable for inclusion in the production of the microarray (Table S01 in Supplementary Material available online at https://doi.org/10.1155/2017/4248756).

2.3. Detection and Quantification Using RT-qPCR. A one-step SYBR Green-based RT-qPCR with melting curve analysis was developed. The QuantiTect SYBR ${ }^{\circledR}$ Green RT-PCR Kit (QIAGEN, Hilden, Germany) was used following the manufacturer's instructions. Briefly, each primer (PFlav-fAAR and PFlav-rKR) was 5'-biotinylated during the initial synthesis (Eurofins Genomics, Ebersberg, Germany) and used at a final concentration of $0.8 \mu \mathrm{M}$, in a final reaction volume of $25 \mu \mathrm{L}$, including $5 \mu \mathrm{L}$ of RNA sample solution. Real-time RTqPCR was carried out on a CFX96 real-time PCR detection system (Bio-Rad Laboratories, Hercules, USA). The thermal cycling profiles are presented in Table 1. Species-specific RTqPCR were also used to determine the sensitivity of the 
Flavivirus RT-qPCR. Reference RNA samples included WNV [22], USUV [26, 34], and TBEV [35]. In order to have comparable $\mathrm{Cq}$ values across experiments, when possible, we set a separate fluorescence cut-off value for each target (PCR primer mix) in each 96-well plate run, such that $\mathrm{Cq}$ $\approx 28$ for the control RNA WNV NY99 diluted $10^{-4}$. This control was previously calibrated using a synthetic RNA [22]. In order to perform Flavivirus quantification, an external standard curve consisting of four dilutions of RNA WNV NY99, $10^{-2}, 10^{-3}, 10^{-4}$, and $10^{-5}$, was included in each run. These were equivalent to $4 \times 10^{4}, 4 \times 10^{3}, 4 \times 10^{2}$, and 40 genome copies $/ \mu \mathrm{L}$ of RNA solution or to $1.4 \times 10^{7}, 1.4 \times 10^{6}$, $1.4 \times 10^{5}$, and $1.4 \times 10^{4}$ copies per $\mathrm{mL}$ of homogenized sample, respectively. To analyze the Flavivirus SYBR Green RT-PCR, the fluorescence was measured at step (6) of the standard protocol (Table 1). Similarly, for species-specific RT-qPCR, fluorescence measurement was conducted at step (4).

2.4. Sequence Analysis. Twenty $\mu \mathrm{L}$ of nonpurified PCR product was sent to Eurofins Genomics (Ebersberg, Germany) for direct DNA sequencing by the Sanger dideoxy method, using the amplification primers. A BLAST (NCBI) search of the obtained sequences was usually sufficient to identify the virus strain. The (internal) amplicon of approximately $240 \mathrm{nt}$ contains sufficient phylogenetic information to reconstruct phylogenetic trees and allows classification of more distantly related and unknown strains and even new species.

2.5. Microarray Analysis. Flavivirus-specific oligonucleotide probes selected using the VisualOligoDeg were spotted onto a low-density microarray of the commercially available ArrayStrip $^{\mathrm{TM}}$ (AS) platform (Alere Technologies $\mathrm{GmbH}$, Jena, Germany). The 84 probes (spots 1-84 in S01 File) were spotted either in triplicate (Chip Wildtech Virology-Mycob 01, from 2011-01-13, assay ID-10610) [36] or in quintuplicate (Chip Wildtech Virology 02, from 2012-09-10, assay ID-16050). The Alere Hybridization Kit was used following previously published instructions [37, 38]. Briefly, only positive RTPCR reactions were routinely analyzed, from which $1 \mu \mathrm{L}$ was directly denatured in $100 \mu \mathrm{L}$ of the hybridization buffer at $95^{\circ} \mathrm{C}$ for $5 \mathrm{~min}$ and then placed for cooling at $4^{\circ} \mathrm{C}$ for $5 \mathrm{~min}$ in a thermocycler (Bio-Rad Laboratories). This solution was transferred to the AS vessel (previously conditioned with water and hybridization buffer) and incubated at $55^{\circ} \mathrm{C}$ for $1 \mathrm{~h}$ upon shaking at $550 \mathrm{rpm}$ on a BioShake iQ heatable shaker (Quantifoil Instruments, Jena, Germany). The AS vessel was subsequently washed twice at $50^{\circ} \mathrm{C}$ for $10 \mathrm{~min}$, incubated with $100 \mu \mathrm{L}$ of a peroxidase conjugate solution at $30^{\circ} \mathrm{C}$ for $10 \mathrm{~min}$, and washed and incubated at room temperature with $100 \mu \mathrm{L}$ of the substrate solution (Seramun Grün; Seramun Diagnostica GmbH, Heidesee, Germany) for $5 \mathrm{~min}$. Images of processed microarrays were saved in bitmap (.bmp) format, using the ArrayMate transmission Reader (Alere Technologies $\mathrm{GmbH}$ ).

2.6. Microarray Data Processing and Flavivirus Identification. The web-based database Pionir, The Experiment Navigator of Partisan Array LIMS (Alere Technologies GmbH), was
TABLE 1: Thermal cycling profiles used in the Flavivirus RT-qPCR.

\begin{tabular}{|c|c|}
\hline Standard $(4.5 \mathrm{~h}, 25 \mu \mathrm{L})$ & Fast $(2.5 \mathrm{~h}, 25 \mu \mathrm{L}$ or $10 \mu \mathrm{L})$ \\
\hline $\begin{array}{l}\text { (1) } 50^{\circ} \mathrm{C} \text { for } 30 \mathrm{~min} \\
\text { (2) } 95^{\circ} \mathrm{C} \text { for } 15 \mathrm{~min} \\
\text { (3) } 95^{\circ} \mathrm{C} \text { for } 15 \mathrm{~s} \\
\text { (4) } 55^{\circ} \mathrm{C} \text { for } 25 \mathrm{~s}+\text { plate read } \\
\text { (5) } 72^{\circ} \mathrm{C} \text { for } 25 \mathrm{~s}+\text { plate read } \\
\text { (6) } 80^{\circ} \mathrm{C} \text { for } 1 \mathrm{~s}+\text { plate read } \\
\text { (7) } \mathrm{GOTO}(3) \text {; } 44 \text { more times } \\
\text { (8) } 95^{\circ} \mathrm{C} \text { for } 1 \mathrm{~min} \\
\text { (9) Melting curve, } 68 \text { to } 88^{\circ} \mathrm{C} \text {, } \\
\text { increment } 0.1^{\circ} \mathrm{C}, 1 \mathrm{~s}+\text { plate read } \\
\text { (10) } 4^{\circ} \mathrm{C} \text { forever (optional) } \\
\text { End }\end{array}$ & $\begin{array}{l}\text { (1) } 50^{\circ} \mathrm{C} \text { for } 30 \mathrm{~min} \\
\text { (2) } 95^{\circ} \mathrm{C} \text { for } 15 \mathrm{~min} \\
\text { (3) } 95^{\circ} \mathrm{C} \text { for } 15 \mathrm{~s} \\
\text { (4) } 55^{\circ} \mathrm{C} \text { for } 20 \mathrm{~s} \\
\text { (5) } 72^{\circ} \mathrm{C} \text { for } 20 \mathrm{~s}+\text { plate read } \\
\text { (6) GOTO (3); } 44 \text { more times } \\
\text { (7) } 95^{\circ} \mathrm{C} \text { for } 1 \text { min } \\
\text { (8) Melting curve, } 68 \text { to } 86^{\circ} \mathrm{C} \text {, } \\
\text { increment } 0.2^{\circ} \mathrm{C}, 1 \mathrm{~s}+\text { plate read } \\
\text { End }\end{array}$ \\
\hline
\end{tabular}

used for visualization and analysis of images and complete experiments, as well as for additional backup. Alongside, the Partisan IconoClust ${ }^{\circledR}$ v3.6r0 software (Alere Technologies $\mathrm{GmbH}$ ) was used for local analysis of microarray images, generating for each spot of each picture the backgroundcorrected signal intensities NI $=1-M / \mathrm{BG}$, with NI being normalized intensity, $M$ average (mean) spot intensity, and BG local background intensity. Spot intensities are measured as light transmission, with $M$ values ranging from 1 for complete transmission (background, weak spots) to 0 for complete absorption (dark spots). Thus, normalized signal intensities range between 0 and 1 . Previous evaluation of the signal to background ratio (SBR) in assays using the same technology has set the cut-off value for positive signals to 0.1 [37]. A custom python script (https://github.com/qPCR4vir/ Flavivirus/blob/master/microarray/icono_clust_scripts/OnlyMeanSignal.icrun) was embedded in this software to enable visualization of individual hybridizations or batch analysis of series of experiments. This script exports experimental data in different formats, including a format suitable for import into Orange software, which allows visual programming and python scripting for data mining and visualization (v2.7.6.dev, installed 2014-06-06 from http://orange.biolab.si/).

Using Orange, the visual program PanFlavExpStdSampl (https://github.com/qPCR4vir/Flavivirus/tree/master/microarray/orange) (Figure S01) was created, which, together with custom modifications of some parts of Orange (https://github .com/qPCR4vir/orange/commit/84f0a20e58b40b238f52319f2017ae77dfodbf72) itself, permits an interactive import of the experiments used as standards (known samples) for parallel analysis with unknown samples for classification. This program calculates the distances between pairs of signal intensity patterns (two microarray experiments), which can serve as a measure of similarity between samples. Several distance formulas are available interactively from Orange and their meaning is explained elsewhere [39]. These distances are visualized in one of the widgets as heat-map-like graphics (Figure 5), in which the labels and the order of the samples can be interactively selected from a group of preoptions. We have added (directly modifying the source code of Orange (https://github.com/qPCR4vir/orange/commit/21c3996c1712baf8819e2050e7dccc31593cf2a0)) the option to reorganize the heat map showing the selected sample at the top followed 
by the most similar samples by mouse-clicking the respective cell. This graphic can also show the samples organized in a tree to reveal clustering. Another Orange widget uses the distances to construct a tree (Figure 4), in which a cut-off can be interactively selected, and/or groups defined to make a report of the proposed classification.

2.7. Field Samples. After development, initial evaluation, and optimization, the new assay was further evaluated by testing RNA extracts from mosquito pools from Greece. Mosquito trapping was performed within the framework of a surveillance program, which was implemented in the region of Central Macedonia during the 2012 arbovirus transmission period. The aims of this program were to molecularly characterize WNV and assess population dynamics of the major arbovirus vector species, to timely notify public health authorities on increased risk [40]. Female adult mosquitoes were collected at dry ice-baited CDC mosquito traps, which were set in areas with previous indications of high arbovirus prevalence [40].

Identified mosquitoes (50 individuals of the same genus) were placed in $2 \mathrm{~mL}$ microcentrifuge tubes with two $4 \mathrm{~mm}$ sterile glass balls and $1 \mathrm{~mL}$ of phosphate-buffered saline (PBS) containing $1 \%$ of heat-inactivated fetal bovine serum (FBS; Sigma-Aldrich, Steinheim, Germany). Disruption was performed for $30 \mathrm{~s}$ at speed 4.0 using a RiboLyser homogenizer (Hybaid, Ltd., Teddington, UK). The homogenates were centrifuged $\left(16,000 \times \mathrm{g}, 5 \mathrm{~min}\right.$ at $\left.4^{\circ} \mathrm{C}\right)$, and $150 \mu \mathrm{L}$ of supernatant from each mosquito pool underwent RNA isolation, based on the previously described RNA extraction method.

In total, 340 mosquito pools were tested with the Flavivirus RT-qPCR protocol. Out of them, 180 pools were represented by Culex mosquitoes, 75 were comprised by Aedes, and 85 were comprised by Anopheles mosquitoes.

\section{Results}

Following preliminary observations that the sensitivity and efficiency of amplification with the primers from [21] were not homogeneous for different flaviviruses, we decided to design a modified set of degenerate primers. Using VisualOligoDeg we selected primers for a modified RT-qPCR for Flavivirus detection and quantification. In the initial experiments, we compared the new procedure with published RT-qPCRs using reference viruses. All 26 Flavivirus reference strains described in Section 2.1 were tested (Figure 1).

The optimized Flavivirus RT-qPCR was also compared in terms of detection limit with species-specific RT-qPCRs for WNV, USUV, and TBEV by testing fresh RNA solutions (from supernatants of infected cells) in a series of end-point dilution experiments (Figures S02 and S03).

Subsequently, we conducted melting curve analysis, which can provide useful information to determine positivity and sequence differences (as shown in Figure 2) but which has limited value for identification. A well-defined peak between 79 and $84^{\circ} \mathrm{C}$ is a strong indication of positivity, and differences in $\mathrm{Tm}$ indicate sequence differences, possibly representing different species or lineages. The results from end-point

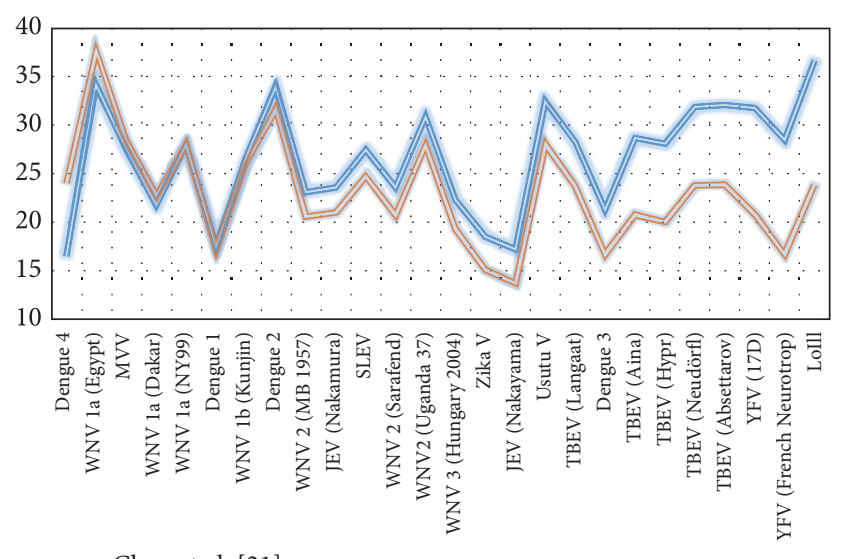

= Chao et al. [21]

$=$ This report

Figure 1: Cq values for 26 viruses. Comparison of $\mathrm{Cq}$ values obtained for different viruses using the protocol of Chao et al. [21] (blue line) with those of our own procedure (red line). The same virus RNA preparation was tested in the same PCR plate with both RT-qPCR protocols. The order of viruses from left to right is according to increasing $\mathrm{Cq}$ difference.

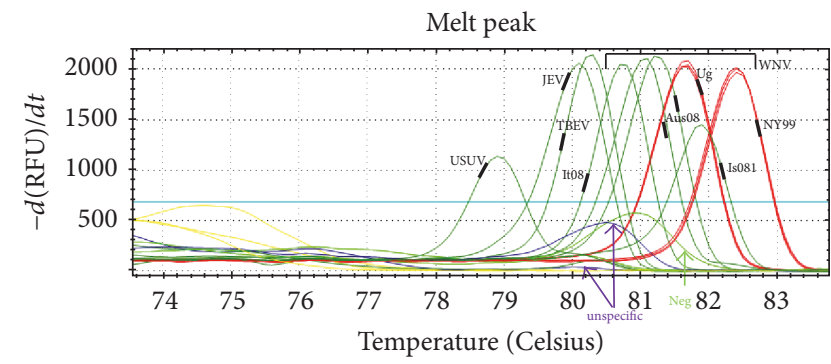

Figure 2: Melting curves from different flaviviruses. Melting curve analysis of the amplicons from different flaviviruses (samples from the ANSES WNV Proficiency Test, 2013). NY99, It08, and Is985 are WNV lineage la strains, while Aus 08 is a lineage 2 strain. The viruses were identified using the microarray, with confirmation by DNA sequencing.

dilution experiments and the calculations using the externally calibrated standard curve suggest that, for most members of Flavivirus genus, this RT-qPCR assay is highly sensitive, capable of detecting a few viral RNA copies per reaction. However, this also means that cross-sample contamination and DNA carryover are a major concern. Therefore, it is crucial to organize the laboratory work accordingly and include sufficient controls to validate the results of each experiment.

To evaluate the accuracy and performance of the developed RT-qPCR assay, we successfully participated in five international ring trials for quality assessment of nucleic acid amplification tests, that is, ANSES 2013 (melting curves of the samples shown in Figure 2), Quality Control for Molecular Diagnostics or QCMD-2010QCMD-2011 [41], QCMD2012, and QCMD-2013 (results summarized in Table S02) (http://www.qcmd.org/). These results complemented the information obtained from WNV-specific RT-qPCRs. Both 
TABLE 2: Screening of mosquito pools collected in Greece. Review of the screening of the 340 mosquito pools (50 mosquitoes each) collected in Greece. All RT-qPCR positive and 6 RT-qPCR negative pools were tested further by microarray and direct sequencing. All other pools tested showed a Cq $>38$ and $\mathrm{Tm}<78^{\circ} \mathrm{C}$.

\begin{tabular}{lccll}
\hline Mosquito pool & $\mathrm{Cq}$ & Tm $\left({ }^{\circ} \mathrm{C}\right)$ & Microarray & DNA sequencing result \\
\hline MPGr.01 & 37.3 & 81.4 & WNV.2 Austria & Nea Santa-Greece-2010 HQ537483 \\
MPGr.02 & 31.6 & 81.6 & WNV.2 Austria & Nea Santa-Greece-2010 HQ537483 \\
MPGr.03 & 21.5 & 81.7 & WNV.2 Austria & Nea Santa-Greece-2010 HQ537483 \\
MPGr.04 & 32.5 & 81.9 & WNV.2 Austria & Nea Santa-Greece-2010 (with 1 mutation) \\
MPGr.05 & 38.5 & 81.6 & WNV.2 Austria & Negative \\
MPGr.06 & 35.6 & 80,4 & ? & Marisma mosquito virus (93\% identity) \\
MPGr.07 & 39.6 & 81.0 & Culex Flav & New Mosq Culex Flavivirus (78\% identity) \\
MPGr.08 & 39.8 & 79.4 & Negative & Negative \\
MPGr.09 & 41.4 & 83.0 & Negative & Negative \\
MPGr.10 & 38.6 & Negative & Negative (residual sequence: Salmonella sp.) \\
MPGr.11 & 40.1 & Negative & Negative \\
MPGr.12 & 40.6 & 79.2 & Negative & Negative \\
MPGr.13 & 39.6 & 80.7 & Negative & Negative (residual sequence: Pseudomonas sp.) \\
\hline
\end{tabular}

WNV and non-WNV Flavivirus strains were quantified using the Flavivirus RT-qPCR with the WNV calibration curve and were subsequently identified by microarray analysis.

The combined RT-qPCR/microarray procedure was applied on the 26 reference virus strains and RT-qPCR positive field samples of diverse origin, in more than 300 hybridization experiments. Each analyzed reference virus produced a specific hybridization pattern that allowed discrimination. Most flaviviruses could be identified at the level of species, genotype, or even strain, following comparison of their hybridization patterns with those of reference samples. A compilation of four Flavivirus isolates each examined at two different RNA dilutions is shown in Figure 3. This figure reveals an important distinction of this microarray platform from well-known glass-slide arrays used for gene expression studies, meaning that the developed microarray is optimized to detect genetic (sequence) variations, rather than the concentration or relative quantity of amplicons. Thus, the present microarray signal intensity values are used solely for identification or classification, while quantification is performed in the preceding RT-qPCR step. As shown in Figure 3, the hybridization patterns are not significantly affected by quantitative variations in the viral load of the sample, but qualitative changes are readily visible when different strains of the same virus species are examined.

In some cases, virus identification is already possible by visually comparing the signal patterns of the bar diagrams (e.g., those in Figure 3). However, given the complexity of the signals, it was necessary to include a computer-based solution for data processing. Orange was used to create a visual program (Figure S01) to import the raw data from the Icono Clust software, to define a set of experimental standards and identify viral samples by clustering (Figure 4). The procedure also permits visualization of mixed of Flavivirus infections in heat-map-like graphics (Figure 5). This capability represents another major advantage of the microarray compared to direct sequencing. Mixes of RNA from closely related Flavivirus strains were tested to explore the possibility of detection of coinfections in a given sample, or detection of the presence of more than one virus in tested pools. We have selected USUV and WNV-1a and WNV-2 (NY99 and Ug37) viruses to show that it is possible to unambiguously detect each component in a mix even of related viruses, such as lineages 1 and 2 of the WNV (Figures 5(b) and 5(c)).

The Flavivirus RT-qPCR screening was conducted on the 340 mosquito pools from Greece. PCR products of 13 mosquito pools (including all positive specimens, as well as six RT-qPCR-negative pools) underwent microarray analysis (Table 2), which revealed the presence of WNV lineage 2 sequences similar to the Austria strain in five of them (MPGr.01-MPGr.05, for $\sim 1.5 \%$ of the total number of pools tested). Culex mosquitoes comprised all five WNV-positive pools. One pool yielded a strong positive result (Cq: 21.5), two were of mediums ( $\mathrm{Cq}-31.6$ and 32.5), and two were of weak concentrations (Cq: 37.3 and 38.5). Sequencing of these five amplicons revealed identity to WNV isolates goshawkHungary/04 DQ116961, Nea Santa-Greece-2010, HQ537483 [42], and Italy $2013 \mathrm{KF} 647248$, in four cases, while the fifth (the one with the highest $\mathrm{Cq}$ value) was not sequenceable.

The microarray also detected weak signals of insectspecific flaviviruses (ISFVs) in two of the pools tested. DNA sequencing revealed the presence of sequences with similarities to the isolate HU4528/07 of Marisma mosquito virus (JN603190, 93\% nucleotide identity) in one Aedes sp. pool (MPGr.06). Additionally, a presumably new mosquito Flavivirus (with only $78 \%$ identity with GQ165809, the Nakiwogo virus strain from Uganda) was also detected in an Anopheles sp. pool (MPGr.07). Flavivirus RT-qPCR/microarray screening of the present panel was completed in less than three working days.

Additionally, other specimens were analyzed, including organs (such as brain, heart, liver, lung, kidney, and spleen) and blood from falcons [24], pheasants, blackbird, great grey owl, common kingfisher, and nearly 70 other avian 


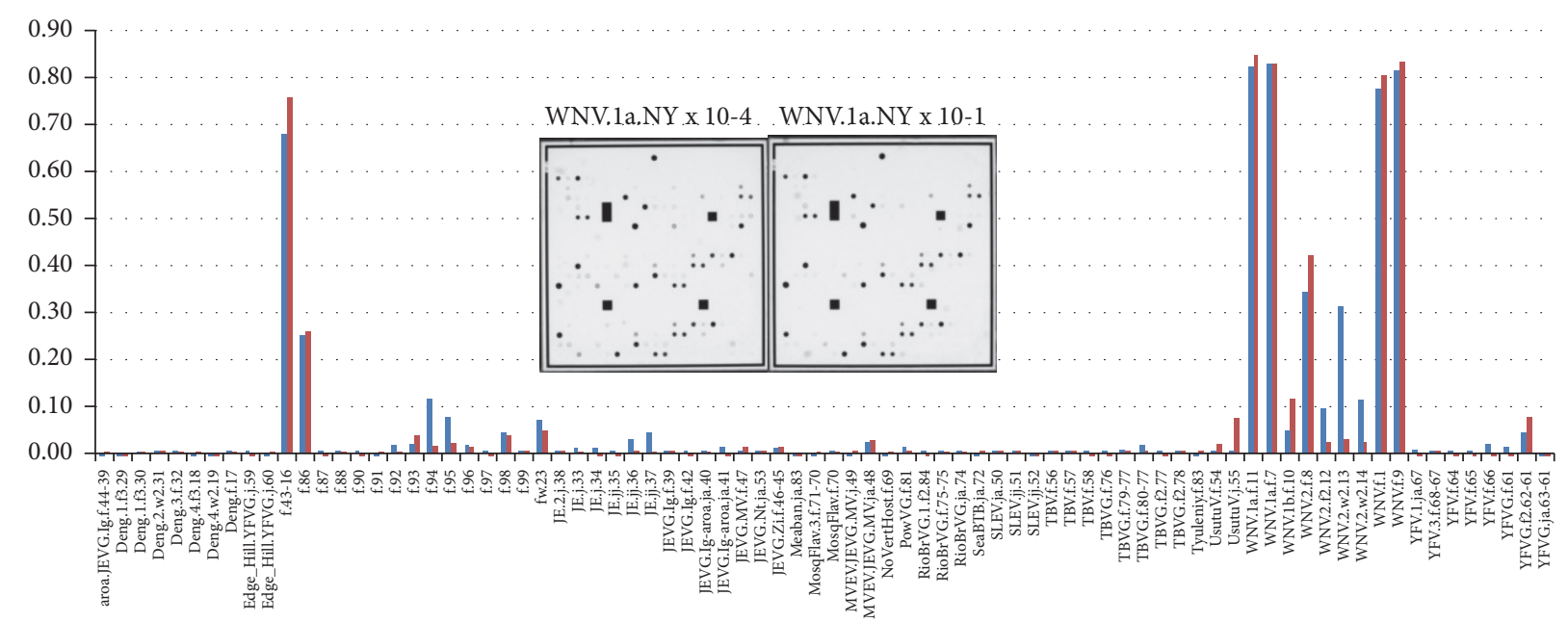

- WNV.1a.NY x 10-4

- WNV.1a.NY x 10-1

(a)

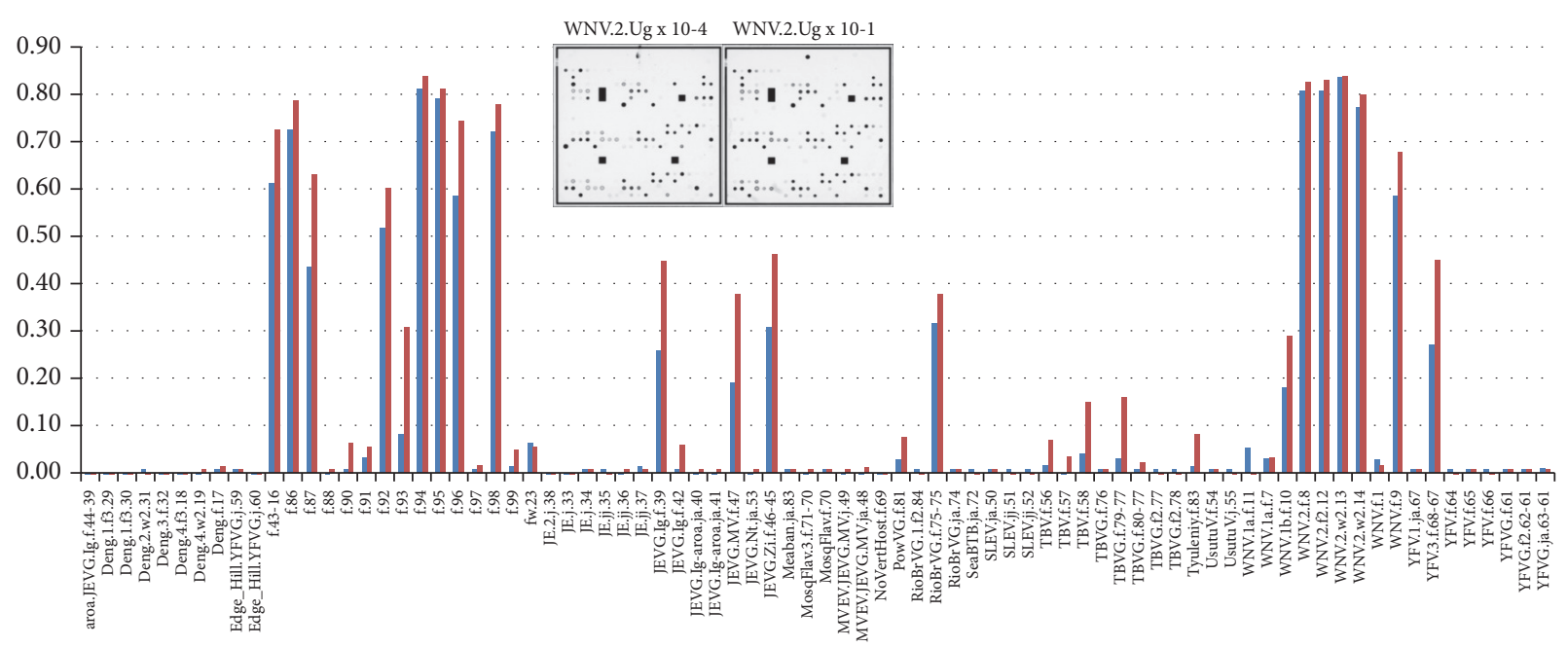

- WNV.2.Ug x 10-4

- WNV.2.Ug x 10-1

(b)

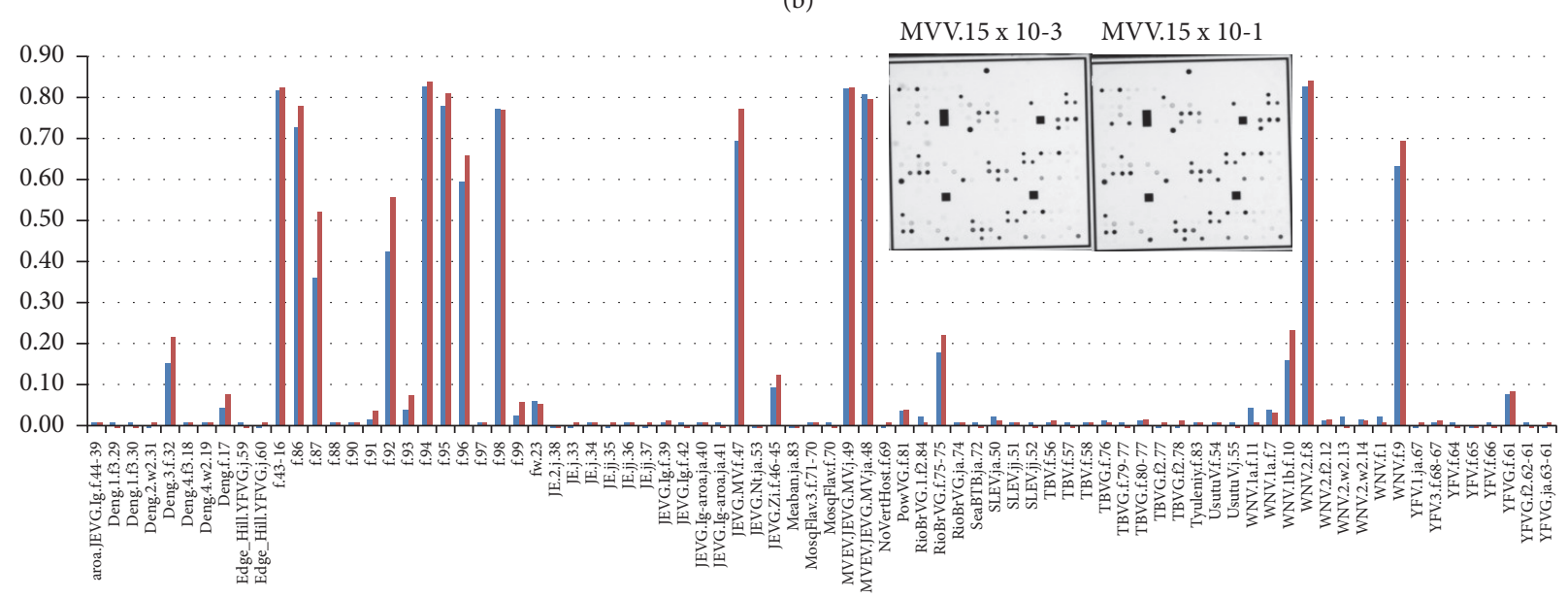

- MVV.15 x 10-3

- MVV. 15 x 10-1 


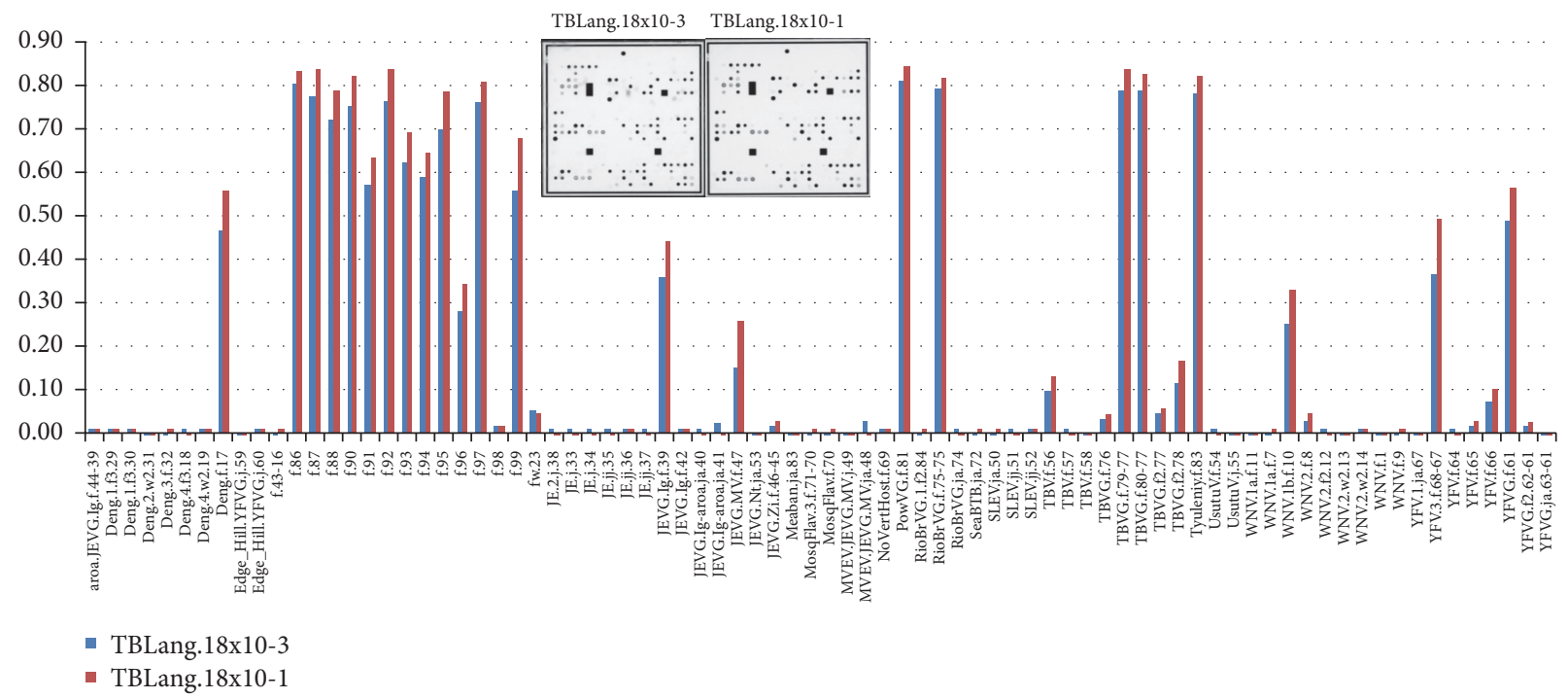

(d)

FIGURE 3: Hybridization patterns for different dilutions of viral samples. Cell culture supernatants: (a) West Nile virus lineage la, strain NY99 (WNV.1a.NY); red bars: sample diluted $10^{-1}$ and blue bars: diluted $10^{-4}$; (b) West Nile virus lineage 2, strain Uganda 1937 (WNV.2.Ug); red bars: $10^{-1}$ and blue bars: $10^{-4}$; (c) Murray Valley encephalitis virus (MVEV); red bars: $10^{-1}$ and blue bars: $10^{-3}$; (d) Tick-borne encephalitis virus, strain Langaat (TBLang); red bars: $10^{-1}$ and blue bars: $10^{-3}$. These data show that hybridization patterns are very sensitive to variation in the viral sequence, while remaining stable in a broad concentration range of viral RNA.

species [6], as well as from mice, camels, horses, donkeys, cattle, humans, mosquitoes, and ticks. Only horse samples have caused artifacts in the RT-qPCR, showing low nonspecific signals $(\mathrm{Cq}>33)$, thus effectively lowering the detection limit of RT-qPCR alone in horse samples to over 50 copies per reaction (data not shown).

\section{Discussion}

By designing the present combined RT-qPCR/microarray assay for detection, quantification, and identification of flaviviruses, a number of methodological problems have been solved. Using VisualOligoDeg, we selected primers and probes for the newly developed assay. The ability of a relatively accurate quantification during the RT-qPCR phase of the assay is one of its major advantages. Technically, the combined RT-qPCR/microarray assay is easy to handle, as only standard experience with real-time PCR and ELISAlike tests is required. We regularly achieved complete testing of samples in one working day, from RNA extraction to final visualization of the tree and interactive heat-map-like graphics.

The present assay permits classification and/or identification up to the (sub)lineage level, avoiding in most cases the need for sequencing. It has been shown to be as sensitive as species-specific RT-qPCRs and suitable for broad-range Flavivirus screening, as well as a confirmatory assay in both laboratory and field samples. The present study has also demonstrated that the assay can be efficiently used in arbovirus surveillance programs, for rapid screening and discrimination of flaviviruses, for example, in mosquito or animal specimens. In areas where numerous arbovirus strains of different virulence cocirculate, such as in Greece and other European countries, molecular identification of the circulating viruses is a necessity [10]. Especially for flaviviral zoonoses, phylogeography and identification of virulent strains are of utmost importance. The assay is also capable of detecting insect-specific flaviviruses. A report on the presence of ISFVs in Culex mosquitoes of Central Macedonia-Greece already exists [43]. Application of RT-qPCR/microarray testing revealed the presence of a virus strain with sequence similarities to Marisma mosquito virus, as well as a presumably novel mosquito Flavivirus sequence, in the same area of Greece. The detection of these ISFVs via the combined $\mathrm{RT}-\mathrm{qPCR} /$ microarray protocol extends our knowledge on the presence of mosquito flaviviruses in Greece. The broad range of flaviviruses that are being tested simultaneously in this assay, in combination with its convenience and the minimum time required for obtaining the results, makes it a useful tool that potentially can be applied widely for surveillance and epidemiological surveys.

While our assay has been proven to be suitable for diagnostic and research laboratories, it represents an open system that can be further improved. In case of newly emerging pathogenic and genetically distinct strains, primer sequences could be further optimized using newly available genome sequences and/or improving probes of those species that were not in the focus of the present study (possibly DENV 4). The number of probes on the microarray is currently at 84 but could be increased to 500 , using the present technology. Since we relied on the specifications of the commercial hybridization kit, we did not perform extensive optimization of the incubation times and temperature and will evaluate the 


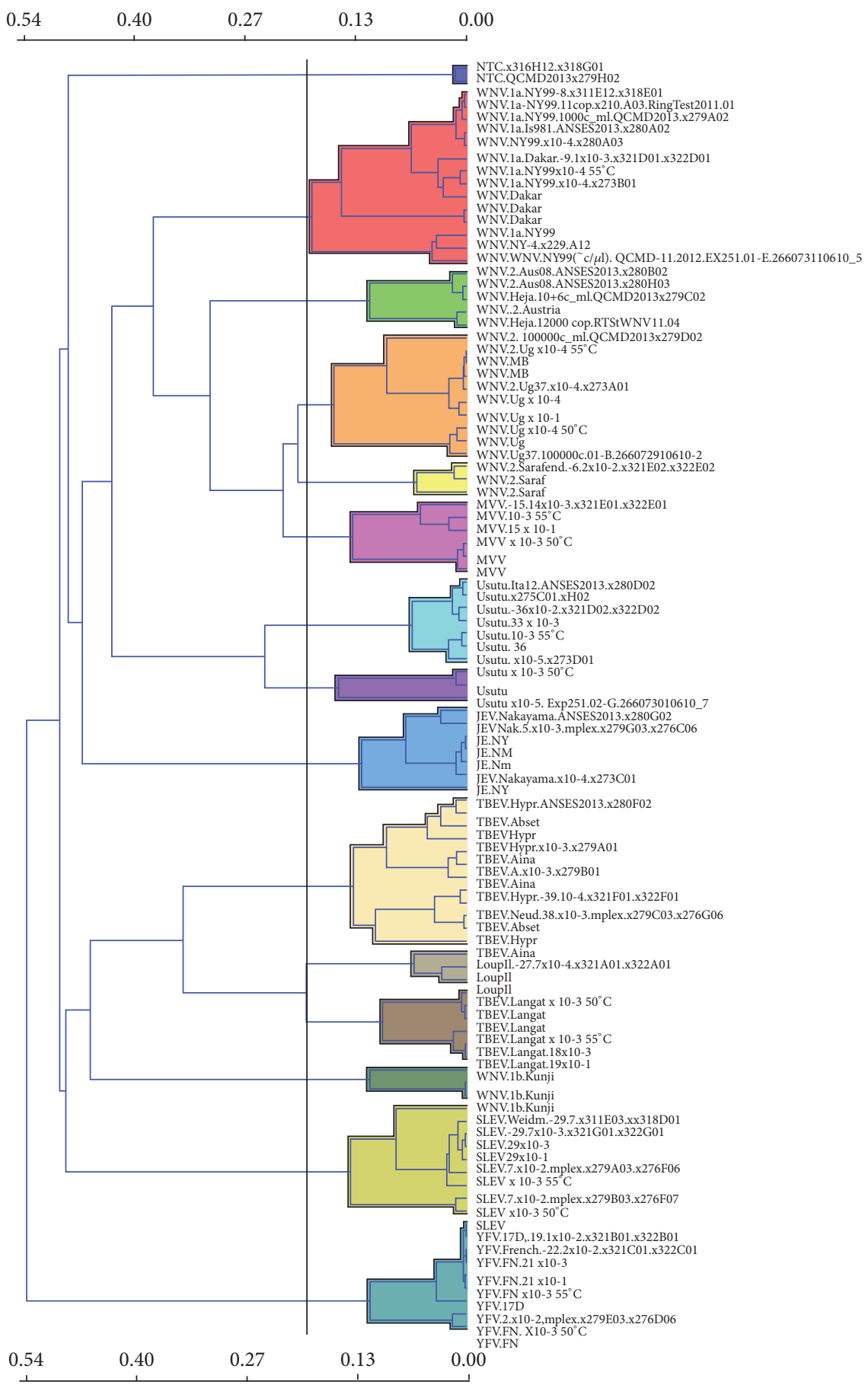

FIGURE 4: Cluster analysis of tested samples. Output of the tree widget in Orange software. A cluster analysis was conducted using the distances between the hybridization patterns of experimentally tested samples. This is the preferred method to visualize the identification of viruses in samples that contain only one Flavivirus.

possibility of using future versions of that kit [44]. A limitation of the present assay is the requirement of experimental hybridizations of known samples, which does not allow direct classification of unknowns. Nevertheless, the methodology is robust enough to allow the use of theoretical hybridization patterns, or those obtained in other laboratories, which could be a solution when a particular virus reference is not available. It should be emphasized that the tree constructed by the
Orange tree widget using the distances between hybridization patterns is not a phylogenetic tree. The graphics just help to group samples according to sequence-based relatedness and thereby facilitates their identification. The Orange software also provides possibilities for classification using machinelearning methods, which have yet to be explored, but they have the potential to significantly improve the accuracy of the final report. 


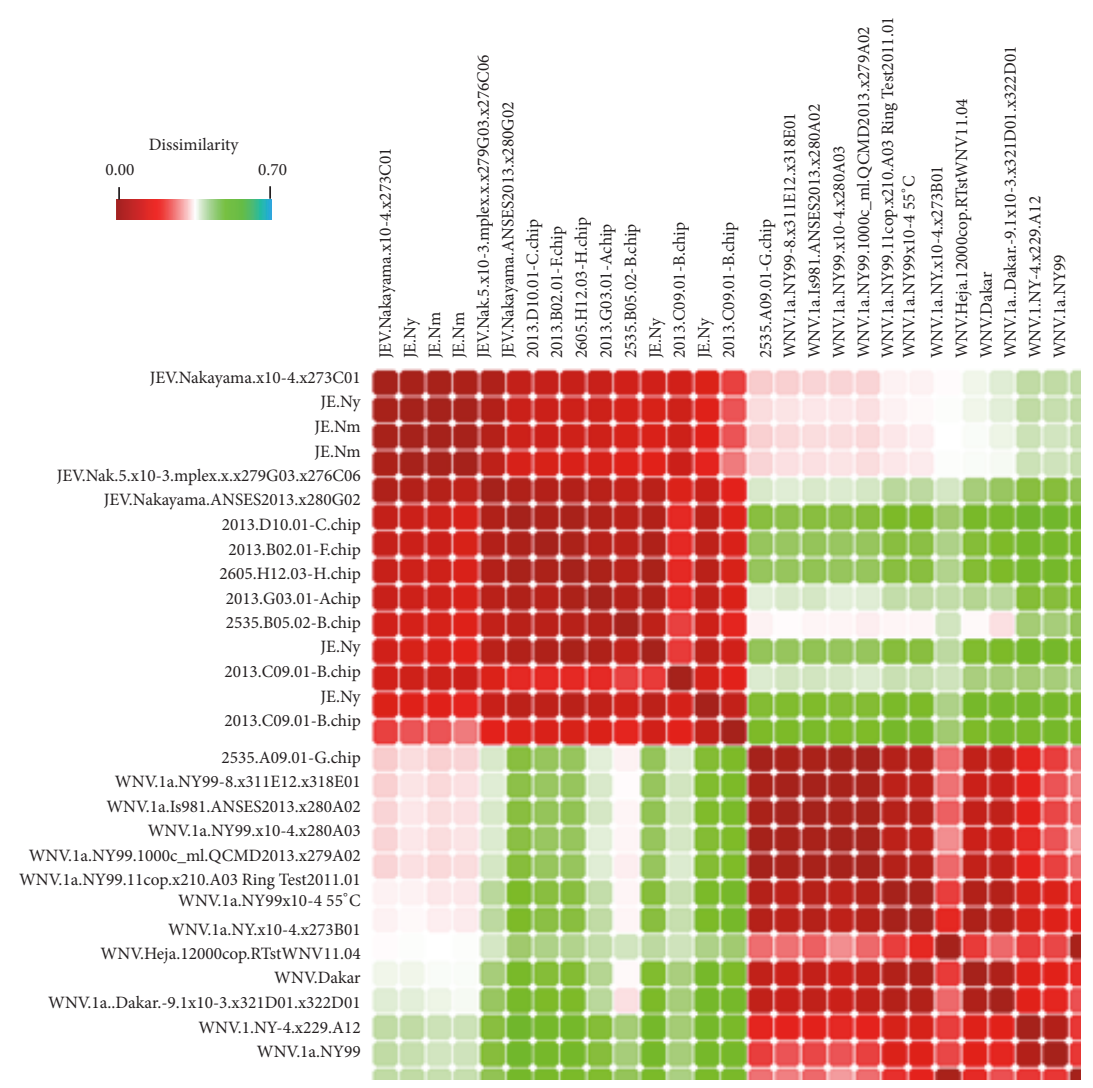

(a)

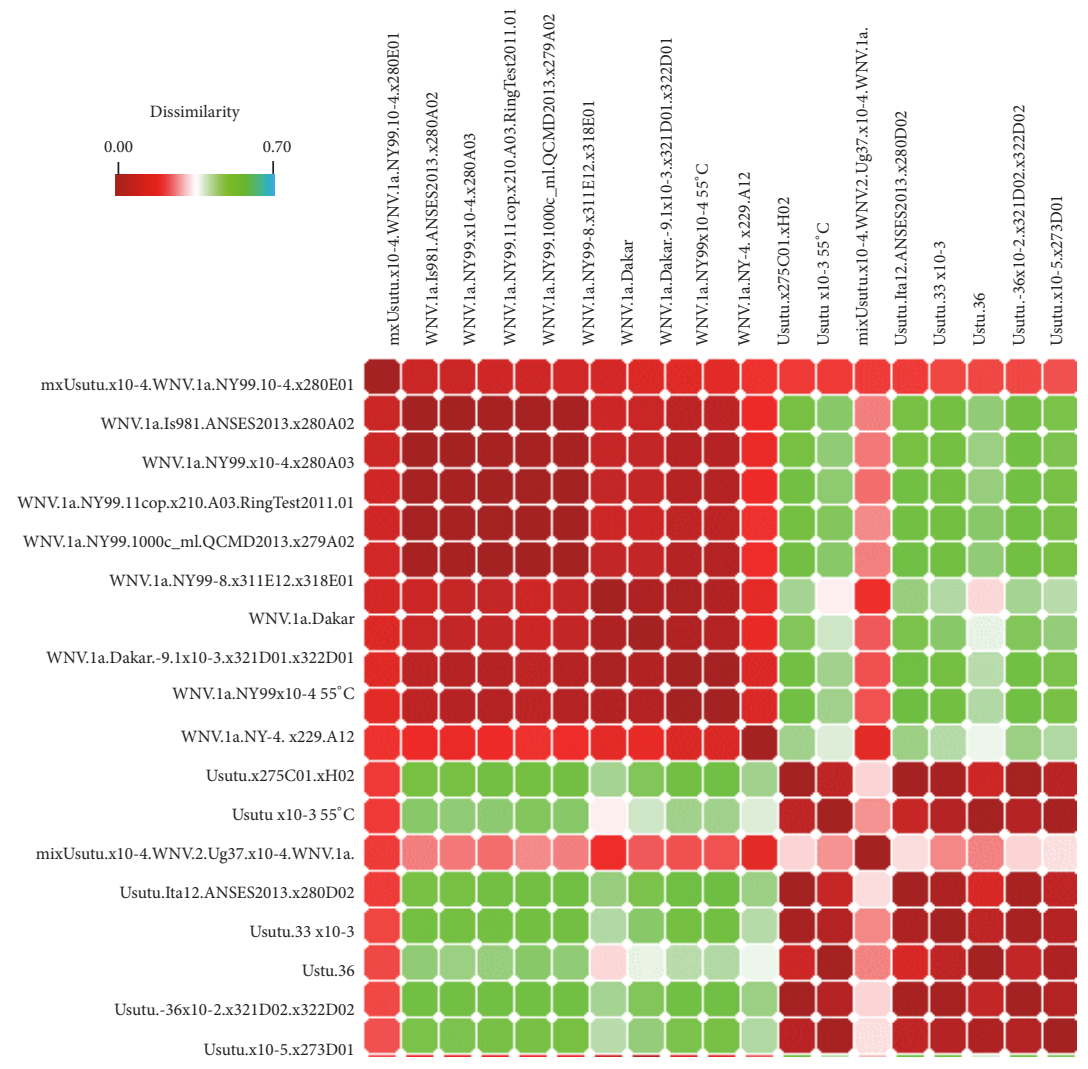

(b)

Figure 5: Continued. 


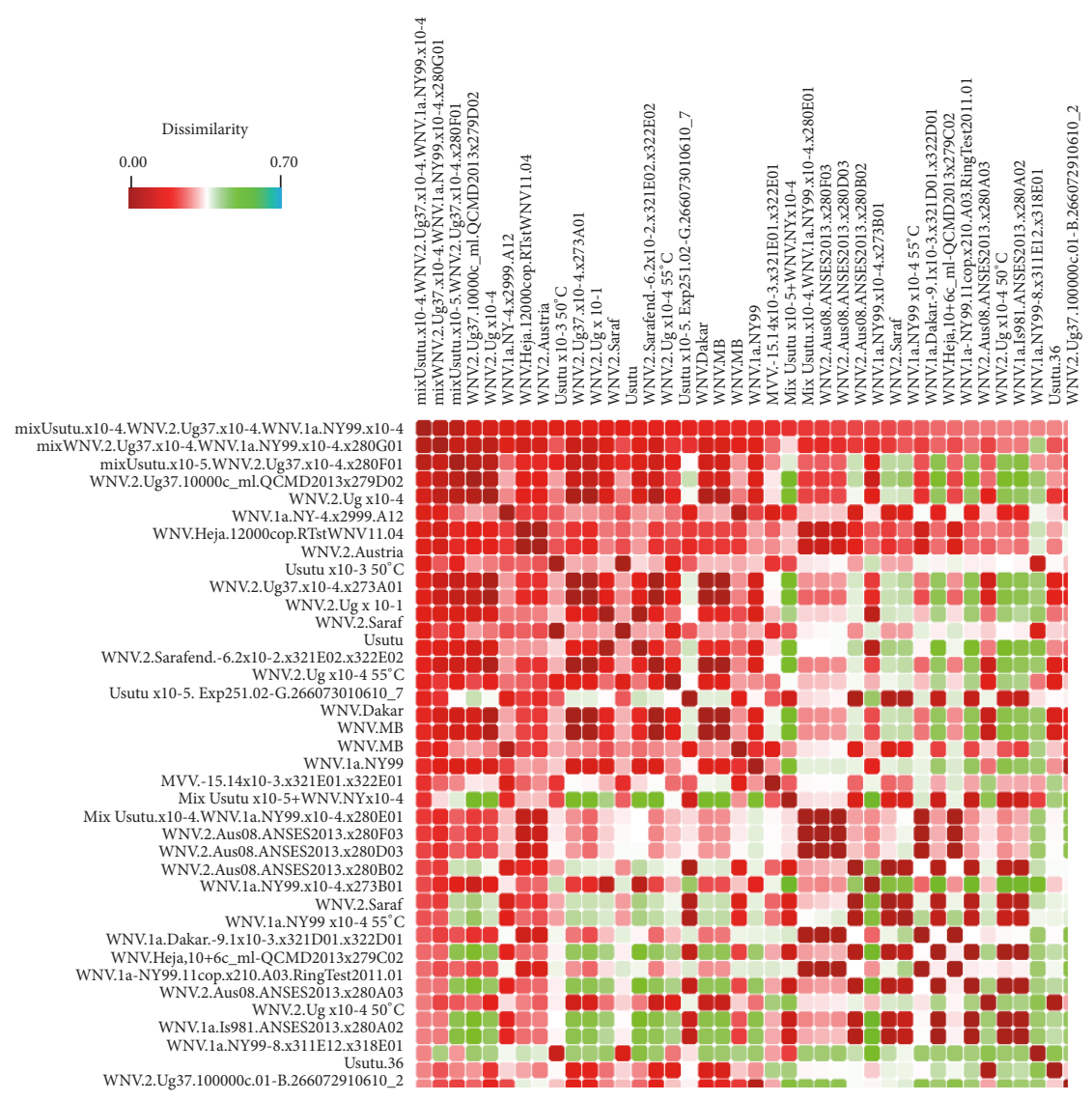

(c)

FIGURE 5: Presentation of experimental results processed by the Orange's heat-map-like widget showing an all-versus-all sample comparison. Calculated distances between intensity patterns of each pair of microarray results obtained from hybridization of sample amplicons are shown, with each cell representing the comparison of two microarray experiments. The dissimilarity color scale is shown at the top. Columns and rows are organized in the same order, making the diagonal an "identity" sample comparison. When one sample is selected by mouse-clicking, the map is immediately reorganized to show this sample in the upper row and left column followed by the most similar samples. (a) The selection of the "JEV.Nakayama.x10-4.x273C01" sample reveals a good separation of JEV samples from all other viral species. (b) The same heat map after selecting a sample containing a mix of diluted USUV and WNV1a RNA, which is easily recognized by a framed mosaic-like map. (c) A more complex mix, including USUV, WNV1, and WNV-2 RNA, was selected showing a more complex pattern that still permits the identification of the components (which can be additionally confirmed by the successive selection of each of the three standard WNV-1, WNV-2, and USUV to check that this mix clusters together with each of them).

Compared to the diagnostic assays for Flavivirus detection published so far, our procedure is distinguished by its high degree of parallelity in detection of a wide range of virus species, strains, and their variations, which cannot be achieved through "one-dimensional" RT-PCR assays [21, $32,45]$. Previously published microarray or diagnostic chip approaches [20] lack the ease of operation of the ArrayStrip platform used here and cover only part of the range of viruses that we can identify $[12,14,19,46]$.

\section{Conclusion}

We have developed a combined RT-qPCR-microarray assay for high-throughput screening and identification of flaviviruses, including mixed infections of different species or strains. Our experience in analyzing field samples (from ticks and mosquito vectors and from human and animal samples of different sources) shows that the assay allows rapid and highly sensitive screening and identification of Flavivirus strains within one day. The assay has helped to overcome limitations in virological diagnosis due to lack of specificity or sensitivity in conventional and real-time RT-PCR protocols. Even if direct sequencing is used as genotyping tool, the developed microarray can be a used as a rapid complementary test to detect mixtures of different Flavivirus strains. The good performance of the assay was also confirmed, by correctly quantifying and identifying members of the Flavivirus genus in samples from international ring trials for quality assessment of nucleic acid amplification tests.

\section{Disclosure}

Konrad Sachse's present address is Department of Bioinformatics for High-Throughput Analysis, Faculty of 
Mathematics and Computer Science, Friedrich-Schiller-Universität, Jena, Germany.

\section{Conflicts of Interest}

The authors declare that they have no conflicts of interest.

\section{Acknowledgments}

Alexandra Chaskopoulou (European Biological Control Laboratory, USDA-ARS, Thessaloniki, Greece) is acknowledged for providing identified mosquitoes.

\section{References}

[1] E. Gould and T. Solomon, "Pathogenic flaviviruses," The Lancet, vol. 371, no. 9611, pp. 500-509, 2008.

[2] M. G. Guzman and E. Harris, "Dengue," The Lancet, vol. 385, no. 9966, pp. 453-465, 2015.

[3] T. P. Monath and P. F. C. Vasconcelos, "Yellow fever," Journal of Clinical Virology, vol. 64, pp. 160-173, 2015.

[4] R. S. Lanciotti, J. T. Roehrig, V. Deubel et al., "Origin of the West Nile virus responsible for an outbreak of encephalitis in the Northeastern United States,' Science, vol. 286, no. 5448, pp. 2333-2337, 1999.

[5] J. N. Hanna, S. A. Ritchie, D. A. Phillips et al., "Japanese encephalitis in north Queensland, Australia, 1998," Medical Journal of Australia, vol. 170, no. 11, pp. 533-536, 1999.

[6] U. Ziegler, H. Jöst, K. Müller et al., "Epidemic spread of usutu virus in Southwest Germany in 2011 to 2013 and monitoring of wild birds for Usutu and West Nile viruses," Vector-Borne and Zoonotic Diseases, vol. 15, no. 8, pp. 481-488, 2015.

[7] M. Marcantonio, A. Rizzoli, M. Metz et al., "Identifying the environmental conditions favouring West Nile Virus outbreaks in Europe," PLoS ONE, vol. 10, no. 3, Article ID e0121158, 2015.

[8] A. S. Fauci and D. M. Morens, "Zika virus in the americas-yet another arbovirus threat," New England Journal of Medicine, vol. 374, no. 7, pp. 601-604, 2016.

[9] S. C. Chaintoutis, C. I. Dovas, M. Papanastassopoulou et al., "Evaluation of a West Nile virus surveillance and early warning system in Greece, based on domestic pigeons," Comparative Immunology, Microbiology and Infectious Diseases, vol. 37, no. 2, pp. 131-141, 2014.

[10] A. Chaskopoulou, C. I. Dovas, S. C. Chaintoutis, J. Kashefi, P. Koehler, and M. Papanastassopoulou, "Detection and early warning of West Nile virus circulation in Central Macedonia, Greece, using sentinel chickens and mosquitoes," Vector-Borne and Zoonotic Diseases, vol. 13, no. 10, pp. 723-732, 2013.

[11] L. G. Glushakova, A. Bradley, K. M. Bradley et al., "Highthroughput multiplexed xMAP Luminex array panel for detection of twenty two medically important mosquito-borne arboviruses based on innovations in synthetic biology," Journal of Virological Methods, vol. 214, pp. 60-74, 2015.

[12] J. J. L. Tan, M. Capozzoli, M. Sato et al., "An integrated lab-onchip for rapid identification and simultaneous differentiation of tropical pathogens," PLoS Neglected Tropical Diseases, vol. 8, no. 7, Article ID e3043, 2014.

[13] N. D. Grubaugh, L. N. Petz, V. R. Melanson et al., "Evaluation of a field-portable DNA microarray platform and nucleic acid amplification strategies for the detection of arboviruses, arthropods, and bloodmeals," American Journal of Tropical Medicine and Hygiene, vol. 88, no. 2, pp. 245-253, 2013.

[14] N. D. Grubaugh, S. S. McMenamy, M. J. Turell, and J. S. Lee, "Multi-gene detection and identification of mosquitoborne RNA viruses using an oligonucleotide microarray," PLoS Neglected Tropical Diseases, vol. 7, no. 8, Article ID e2349, 2013.

[15] D. D. Singh and A. Jain, "Multipurpose instantaneous microarray detection of acute encephalitis causing viruses and their expression profiles," Current Microbiology, vol. 65, no. 3, pp. 290-303, 2012.

[16] J. Teo, P. D. Pietro, F. S. Biagio et al., "VereFlu ${ }^{\mathrm{TM}}$ : an integrated multiplex RT-PCR and microarray assay for rapid detection and identification of human influenza A and B viruses using lab-onchip technology," Archives of Virology, vol. 156, no. 8, pp. 13711378, 2011.

[17] X. Kang, C. Qin, Y. Li et al., "Improvement of the specificity of a pan-viral microarray by using genus-specific oligonucleotides and reduction of interference by host genomes," Journal of Medical Virology, vol. 83, no. 9, pp. 1624-1630, 2011.

[18] X.-P. Kang, Y.-Q. Li, Q.-G. Sun, H. Liu, Q.-Y. Zhu, and Y.H. Yang, "Development of a consensus microarray method for identification of some highly pathogenic viruses," Journal of Medical Virology, vol. 81, no. 11, pp. 1945-1950, 2009.

[19] H. Nordström, K. I. Falk, G. Lindegren et al., "DNA microarray technique for detection and identification of seven flaviviruses pathogenic for man," Journal of Medical Virology, vol. 77, no. 4, pp. 528-540, 2005.

[20] J. Korimbocus, N. Scaramozzino, B. Lacroix, J. M. Crance, D. Garin, and G. Vernet, "DNA probe array for the simultaneous identification of herpesviruses, enteroviruses, and flaviviruses," Journal of Clinical Microbiology, vol. 43, no. 8, pp. 3779-3787, 2005.

[21] D.-Y. Chao, B. S. Davis, and G.-J. J. Chang, "Development of multiplex real-time reverse transcriptase PCR assays for detecting eight medically important flaviviruses in mosquitoes," Journal of Clinical Microbiology, vol. 45, no. 2, pp. 584-589, 2007.

[22] M. Eiden, A. Vina-Rodriguez, B. Hoffmann, U. Ziegler, and M. H. Groschup, "Two new real-time quantitative reverse transcription polymerase chain reaction assays with unique target sites for the specific and sensitive detection of lineages 1 and 2 West Nile virus strains," Journal of Veterinary Diagnostic Investigation, vol. 22, no. 5, pp. 748-753, 2010.

[23] K. Schmidt, M. Keller, B. L. Bader et al., "Integrins modulate the infection efficiency of West Nile virus into cells," Journal of General Virology, vol. 94, no. 8, pp. 1723-1733, 2013.

[24] U. Ziegler, J. Angenvoort, D. Fischer et al., "Pathogenesis of West Nile virus lineage 1 and 2 in experimentally infected large falcons," Veterinary Microbiology, vol. 161, no. 3-4, pp. 263-273, 2013.

[25] N. Becker, H. Jöst, U. Ziegler et al., "Epizootic emergence of Usutu virus in wild and captive birds in Germany," PLOS ONE, vol. 7, no. 2, Article ID e32604, 2012.

[26] H. Jöst, A. Bialonski, D. Maus et al., "Isolation of usutu virus in Germany," American Journal of Tropical Medicine and Hygiene, vol. 85, no. 3, pp. 551-553, 2011.

[27] U. Ziegler, A. Skrypnyk, M. Keller et al., "West nile virus antibody prevalence in horses of Ukraine," Viruses, vol. 5, no. 10, pp. 2469-2482, 2013.

[28] B. Hoffmann, K. Depner, H. Schirrmeier, and M. Beer, "A universal heterologous internal control system for duplex realtime RT-PCR assays used in a detection system for pestiviruses," 
Journal of Virological Methods, vol. 136, no. 1-2, pp. 200-209, 2006.

[29] J. D. Thompson, T. J. Gibson, F. Plewniak, F. Jeanmougin, and D. G. Higgins, "The CLUSTAL X windows interface: flexible strategies for multiple sequence alignment aided by quality analysis tools," Nucleic Acids Research, vol. 25, no. 24, pp. 48764882, 1997.

[30] T. A. Hall, "BioEdit: a user-friendly biological sequence alignment editor and analysis program for Windows 95/98/NT," Nucleic Acids Symposium Series, vol. 41, pp. 95-98, 1999.

[31] C. Domingo, P. Patel, S. Linke, K. Achazi, and M. Niedrig, "Molecular diagnosis of flaviviruses," Future Virology, vol. 6, no. 9, pp. 1059-1074, 2011.

[32] P. Patel, O. Landt, M. Kaiser et al., "Development of one-step quantitative reverse transcription PCR for the rapid detection of flaviviruses," Virology Journal, vol. 10, article no. 58, 2013.

[33] M. P. Sánchez-Seco, D. Rosario, C. Domingo et al., "Generic RT-nested-PCR for detection of flaviviruses using degenerated primers and internal control followed by sequencing for specific identification," Journal of Virological Methods, vol. 126, no. 1-2, pp. 101-109, 2005.

[34] F. Cavrini, M. E. Della Pepa, P. Gaibani et al., "A rapid and specific real-time RT-PCR assay to identify Usutu virus in human plasma, serum, and cerebrospinal fluid," Journal of Clinical Virology, vol. 50, no. 3, pp. 221-223, 2011.

[35] M. Schwaiger and P. Cassinotti, "Development of a quantitative real-time RT-PCR assay with internal control for the laboratory detection of tick borne encephalitis virus (TBEV) RNA," Journal of Clinical Virology, vol. 27, no. 2, pp. 136-145, 2003.

[36] A. Ruettger, J. Nieter, A. Skrypnyk et al., "Rapid spoligotyping of Mycobacterium tuberculosis complex bacteria by use of a microarray system with automatic data processing and assignment," Journal of Clinical Microbiology, vol. 50, no. 7, pp. 24922495, 2012.

[37] C. Schnee, S. Schulsse, H. Hotzel et al., "A novel rapid dna microarray assay enables identification of 37 mycoplasma species and highlights multiple mycoplasma infections," PLoS ONE, vol. 7, no. 3, Article ID e33237, 2012.

[38] C. Schnee and K. Sachse, "DNA microarray-based detection of multiple pathogens: Mycoplasma spp. and Chlamydia spp.", in Veterinary Infection Biology: Molecular Diagnostics and HighThroughput Strategies, vol. 1247 of Methods in Molecular Biology, pp. 193-208, Springer, 2015.

[39] A. Urisman, K. F. Fischer, C. Y. Chiu et al., "E-Predict: a computational strategy for species identification based on observed DNA microarray hybridization patterns," Genome Biology, vol. 6, no. 9, article R78, 2005.

[40] S. C. Chaintoutis, A. Chaskopoulou, T. Chassalevris, P. G. Koehler, M. Papanastassopoulou, and C. I. Dovas, "West nile virus lineage 2 strain in Greece, 2012," Emerging Infectious Diseases, vol. 19, no. 5, pp. 827-829, 2013.

[41] S. Linke, W. G. MacKay, C. Scott, P. Wallace, and M. Niedrig, "Second external quality assessment of the molecular diagnostic of West Nile virus: are there improvements towards the detection of WNV?" Journal of Clinical Virology, vol. 52, no. 3, pp. 257-260, 2011.

[42] A. Papa, T. Bakonyi, K. Xanthopoulou, A. Vázquez, A. Tenorio, and N. Nowotny, "Genetic characterization of west nile virus lineage 2, Greece, 2010," Emerging Infectious Diseases, vol. 17, no. 5, pp. 920-922, 2011.
[43] A. Papa, E. Papadopoulou, S. Kalaitzopoulou, K. Tsioka, and S. Mourelatos, "Detection of West Nile virus and insectspecific flavivirus RNA in Culex mosquitoes, central Macedonia, Greece," Transactions of the Royal Society of Tropical Medicine and Hygiene, vol. 108, no. 9, pp. 555-559, 2014.

[44] I. V. Jani, B. Meggi, A. Vubil et al., "Evaluation of the wholeblood alere q nat point-of-care RNA assay for HIV-1 viral load monitoring in a primary health care setting in Mozambique," Journal of Clinical Microbiology, vol. 54, no. 8, pp. 2104-2108, 2016.

[45] M. W. Gaunt and E. A. Gould, "Rapid subgroup identification of the flaviviruses using degenerate primer E-gene RT-PCR and site specific restriction enzyme analysis," Journal of Virological Methods, vol. 128, no. 1-2, pp. 113-127, 2005.

[46] A. J. Foord, V. Boyd, J. R. White, D. T. Williams, A. Colling, and H. G. Heine, "Flavivirus detection and differentiation by a microsphere array assay," Journal of Virological Methods, vol. 203, pp. 65-72, 2014. 

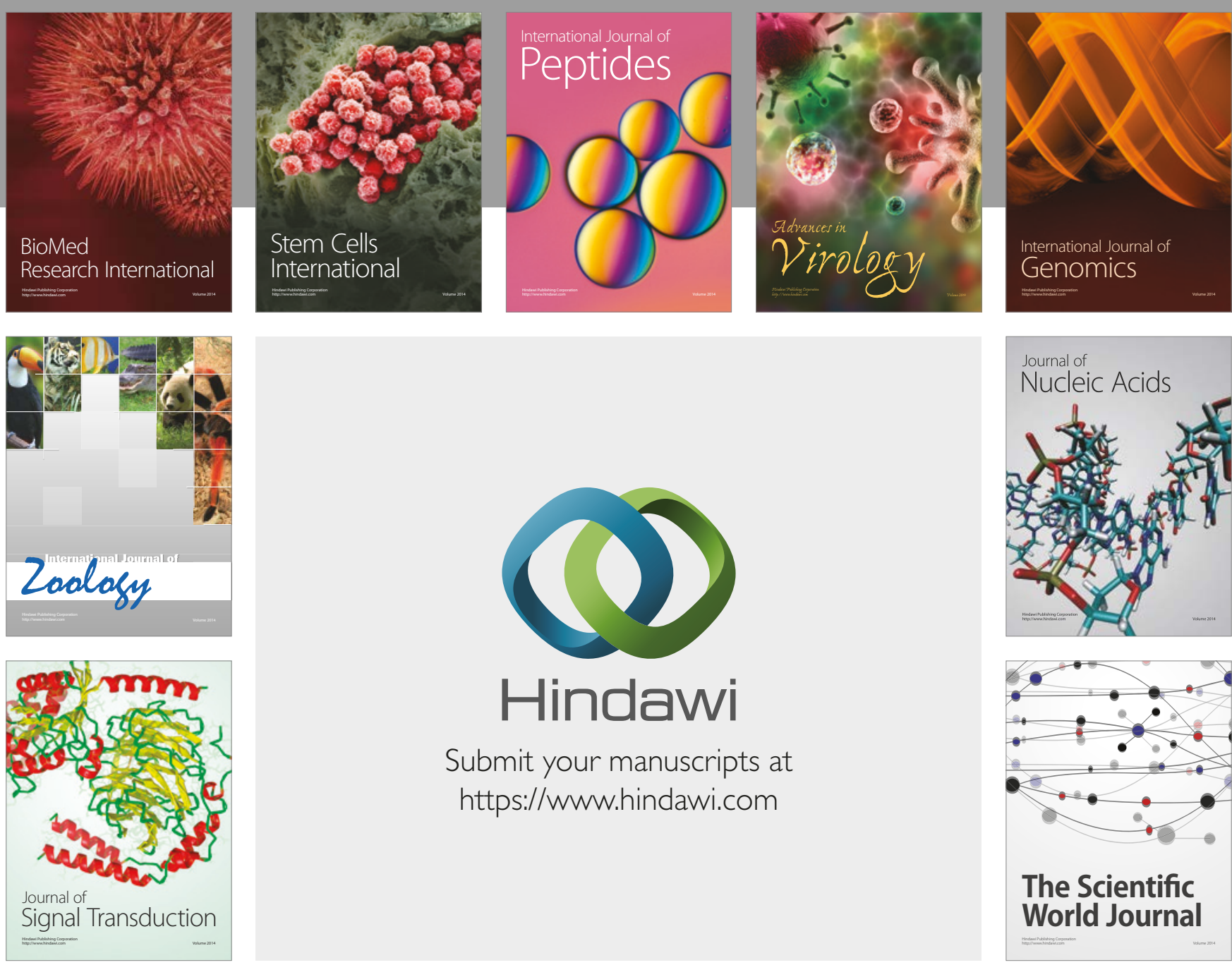

Submit your manuscripts at

https://www.hindawi.com
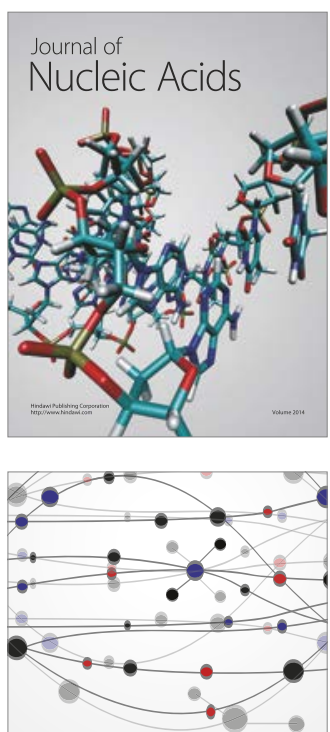

The Scientific World Journal

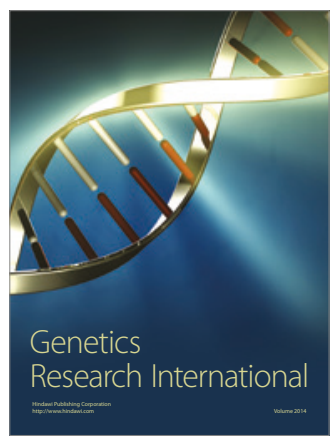

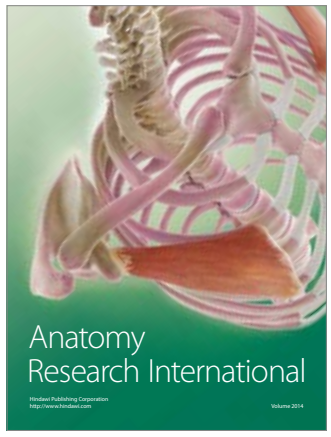

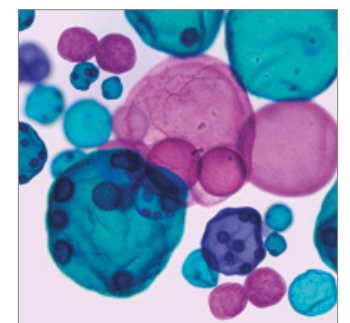

International Journal of Microbiology
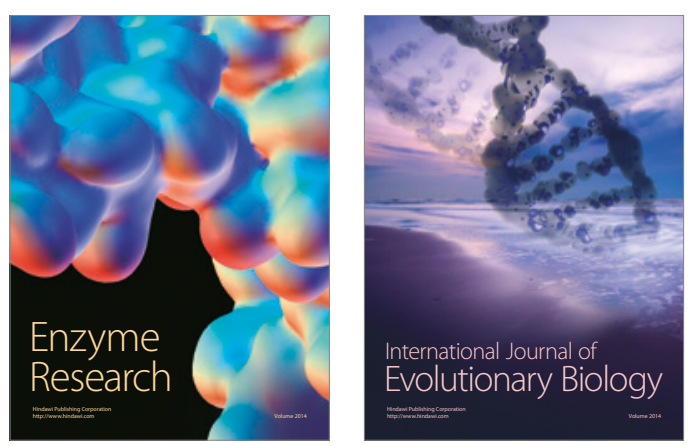
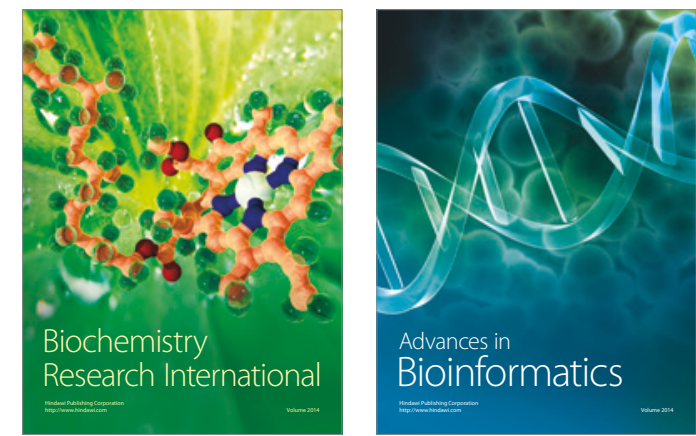

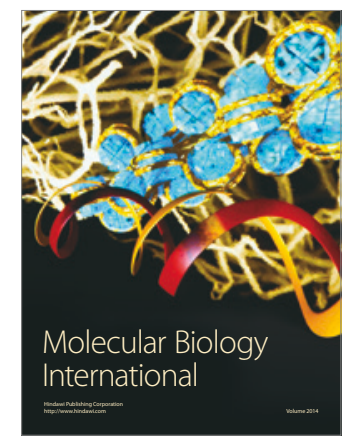

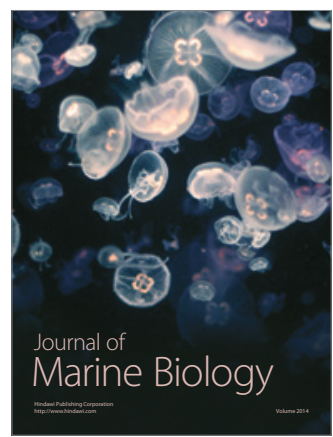

